Epistemology according to bistorical reason

\title{
La epistemología de la razón histórica
}

David Antonio Yáñez Baptista

UCM-UNED

david_maca@hotmail.com

DOI: http://dx.doi.org/10.15366/bp2018.18.016

Bajo Palabra. II Época. No18. Pgs: 321-336

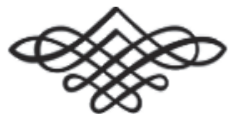


Recibido: 17/08/2017

Aprobado: 29/07/2018

\section{Resumen}

El conocimiento no es algo natural, sino uno de los modos de pensar a los que el hombre ha llegado en el curso de sus experiencias vitales. De este modo, tanto el conocimiento como su correlato, el ser de las cosas, son dos creencias históricas, y ésta es una de las grandes diferencias entre la metafísica de Ortega y Gasset y el pensamiento de Martin Heidegger.

Palabras clave: pensamiento, conocimiento, razón, Ortega, Heidegger.

\section{Abstract}

Knowledge is not natural, but one of the ways of thinking achieved by man throughout the course of his vital experiences. Thus, both knowledge and his object, the being of things, are two historical beliefs. This is one of the big differences between Ortega's metaphysics and Martin Heidegger's thought.

Keywords: thought, knowledge, reason, Ortega, Heidegger. 


\section{Introducción}

Decía Ortega que la filosofía no es Una Ciencia, sino una indecencia, porque todas las cosas, todas las realidades, las deja como vinieron al mundo: desnudas. ${ }^{1}$ Por eso, el mejor nombre que se haya dado a la verdad, esa verdad que la filosofía busca, se lo pusieron los griegos hace más de dos mil años, cuando llamaron a la verdad $\alpha \dot{\lambda} \theta \dot{\theta} \varepsilon \alpha$, es decir, descubrimiento. Uno de los fenómenos que podemos poner al descubierto es el conocimiento; ésa es la labor de la epistemología o gnoseología, o, dicho con más sencillez, de la teoría del conocimiento.

El conocimiento es la abstracción del conocer como el sustantivo es la abstracción del verbo. El verbo, a su vez, sigue siendo abstracto si no se concreta, si no se individúa en la vida de un hombre. No se trata, por tanto, del conocimiento en general, sino del esfuerzo que yo hago, con mis aparatos mentales, para conocer una determinada realidad. Por eso Ortega distinguía el 'hacer' de la mera 'actividad'. ${ }^{2}$ La actividad se convierte en hacer cuando no se dispara mecánicamente sino guiada por mi voluntad. Respiro automáticamente, pero puedo hacerlo lenta y profundamente cuando el médico me lo pide para auscultarme. Si quiero desplazarme, mi voluntad pone en marcha la actividad de caminar, pero ésta también se verifica en los sonámbulos. Lo mismo acontece con las actividades psíquicas. Mi inteligencia, mi imaginación y mi memoria funcionan por su cuenta; otra cosa es que yo me ponga a hacer algo con esas facultades, como hacen el intelectual, el novelista y el hombre que escribe sus memorias. ${ }^{3}$

Los mecanismos mentales han sido una de las ocultaciones del conocimiento. ${ }^{4}$ Para ejecutar éste es preciso movilizar unas facultades, pero el conocimiento no se reduce a ellas; por eso una epistemología que se limite a la descripción de las potencias psicológicas del hombre carece de la radicalidad necesaria para mostrar la consistencia de los fenómenos estrictamente filosóficos. Lo cierto es que toda ocupación con cualquier ingrediente de mi circunstancia -incluyendo en ella no sólo

\footnotetext{
${ }^{1}$ Cf. Ortega y Gasset, J., El hombre y la gente, en Obras Completas X, Madrid, Taurus y Fundación J. Ortega y Gasset, 2010, p. 202 (en adelante, las referencias a esta edición de las Obras Completas se harán con el tomo en números romanos y las páginas en arábigos).

2 Cf. Ortega y Gasset, J., Principios de metafísica según la razón vital Lecciones del curso 1933-34, en O.C. IX, pp. $49-53$.

3 Ídem.

${ }^{4}$ Cf. Ortega y Gasset, J., Apuntes sobre el pensamiento: su teúrgia y su demiurgia, en O.C. VI, p. 10 -14.
} 
lo que solemos llamar 'mundo exterior', sino también mi cuerpo y mi psique- es siempre una pre-ocupación por mi propio ser. Ahora hago algo con las cosas y las demás personas, movilizando con ello mis aparatos físicos y psíquicos, porque así voy revelando una determinada figura de mí mismo. Entonces el hombre no tiene naturaleza, sino historia. El hombre va siendo lo que va haciendo de sí mismo; es un artista, original o plagiario, de su propia existencia. Esta existencia adquirió una nueva figura hace ya más de dos mil ańos, una forma de vida distinta de la primitiva, que ya no era mágica, ni visionaria, ni mitológica: el hombre inventó la vida contemplativa. Una teoría del conocimiento que esté a la altura de los tiempos tiene que dar cuenta y razón de esta historicidad del homo theoreticus. Por eso, el análisis psicológico de las facultades que intervienen en el conocimiento es insuficiente, como lo es el análisis lógico de las condiciones de su pretensión de verdad. ${ }^{5}$ Todo esto da por supuesto el conocimiento sin radicarlo en la vida humana, que es histórica. Es preciso recordar lo que Ortega advertía: que todos los problemas filosóficos tienen sus raíces en el estudio de la vida, es decir, en la metafísica de la razón vital e histórica. ${ }^{6}$

\section{La raíz metafísica del pensamiento}

¿QUÉ es LA METAFÍsICA? La palabra 'metafísica', como cualquier otra, está embarazada de significados históricamente heredados, fecundada por mentes innovadoras en tiempos pretéritos y siempre presta a dar a luz en el momento en que la utilicemos. Pero por esta palabra no corre nuestra sangre, sino la ajena; lleva significados bastardos e ilegítimos. Nos ocurre esto cuando la metafísica sólo es una disciplina ya hecha que repetimos al aprenderla; sin embargo, la metafísica, como todo lo humano, no está hecha: es algo que hay que hacer. Fecundemos la metafísica con nuevos sentidos. Si nos limitamos a repetir y comentar escolásticamente una metafísica, nos falsificamos con lo que hacemos, porque renunciamos a hacerlo nosotros. Pero no debemos tener prurito de originalidad, porque desvirtúa la pureza de la vocación intelectual. Ocuparse de lo que otros han pensado es haber empezado ya a pensar, es decir, a filosofar. Y para poder afrontar intelectualmente un problema es menester estar a la altura que la circunstancia exige de nosotros, y para ello hay que recorrer la serie de soluciones -algunas, aprovechables, íntegra o parcialmente; otras, desechables- que los pensadores más destacados forjaron en otros tiempos.

\footnotetext{
5 Ídem.

${ }^{6}$ Cf. Ortega y Gasset, J., ¿Qué es la vida? Lecciones del curso 1930-1931, en O.C. VII, p. 447.
} 
En este sentido, la filosofía necesita de su historia, y el que la recorre y se instala en un pensamiento que está a la altura, aunque no sea el suyo, en cierto modo también lo es, porque lo hace suyo integrándolo en su perspectiva. Ahí está la originalidad.

La metafísica de Ortega, pensada en español y hecha para los españoles -por tanto, circunstancialmente- significó la posibilidad de la filosofía en España. ${ }^{7}$ No se trata de una metafísica sólo porque se ocupe de entes que están más allá de lo físico. Con ello se recae en la ontología, que es una interpretación histórica de la metafísica. La metafísica de Ortega responde al sentido que Aristóteles quiso dar a esta disciplina cuando todavía no estaba hecha: zetouméne episteme, es decir, la ciencia buscada. ${ }^{8}$ Toda ciencia se define por su objeto. La metafísica, a lo largo de la historia del pensamiento, ha ido cambiando de objeto, por tanto, va ella misma cambiando, siendo otra que la que antes era. La metafísica, al ir en busca de su objeto, va en busca de sí misma. Este objeto no es otro que la realidad de las realidades, cuya ciencia ha de ser autónoma y pantónoma, última e integral. ${ }^{9}$ El objeto de la metafísica es la realidad radical: es mi vida.

Ortega nos ofreció en 1914, en sus Meditaciones del Quijote, la fórmula que reúne en un punto de máxima densidad la riqueza de su pensamiento metafísico: 'yo soy yo y mi circunstancia, y si no la salvo a ella, no me salvo yo'. ${ }^{10} \mathrm{El}$ primer 'yo' significa 'mi vida', el segundo 'yo' se refiere al 'proyecto', y la circunstancia es todo aquello con lo cual ejecuto el proyecto que soy. 'Yo soy yo y mi circunstancia' significa, por tanto, que mi vida en el momento presente es la ejecución de quién pretendo ser en la circunstancia en la que me toca vivir, con las cosas y las demás personas. Pero Ortega ańade: si no salvo mi circunstancia tampoco me salvo yo. Acordándose de los platónicos, Ortega pide que salvemos las apariencias, esto es, que busquemos el sentido de los que nos rodea; que interpretemos la circunstancia convirtiéndola en mundo. ${ }^{11}$

El hombre no puede hacer nada sin un mundo, o lo que es igual, el hombre sin mundo no es alguien, es nadie. ¿¿Por qué? Porque el hombre no puede interpretarse a sí mismo sin una mínima interpretación de su circunstancia, no de algunos de sus aspectos particulares, sino de todo cuanto hay. Lo particular se aclara en vista de la totalidad. Esta interpretación que la vida hace de sí misma, de la circunstancia y del yo, es lo que Ortega llama razón vital. La vida, al hacerse, está siempre autointepretándose, sabiéndose y aclarándose a sí misma; por eso razón y vida son dos si-

\footnotetext{
7 Cf. Marías, J., Historia de la filosofía, Alianza Editorial, Madrid, 2008, p. 401.

8 Cf. 983a21, 995a24, 996b3.

9 Cf. Vida como ejecución (el ser ejecutivo). Lecciones del curso 1929-1930, en íbid., p.207; ¿Qué es filosofía?, en íbid., p. 278-290.

${ }^{10}$ Cf. Ortega y Gasset, J., Meditaciones del Quijote, en O.C. I, p. 757.

11 Ídem.
} 
nónimos. Ésto, que por lo pronto puede parecer la doctrina madura de Ortega, está ya, in statu nascendi, en un artículo bien temprano, de 1910, titulado "Adán en el paraíso". Allí Ortega diferencia entre 'percatarse' y 'saber'. "Ni la piedra ni el animal se percatan de que viven", nos dice Ortega. ${ }^{12}$ En rigor, sólo el hombre vive, criatura hecha a imagen y semejanza de Dios. Dios, según el filósofo madrileño, es "el nombre que damos a la capacidad de hacerse cargo de las cosas". ${ }^{13}$ Pero el hombre no es Dios, es como Dios. Al vivir, se da cuenta de que vive, es decir, de que está en una circunstancia teniendo que hacer algo con ella, a saber, la propia vida, pero lo que tengo que hacer y lo que la circunstancia es, eso el hombre lo desconoce. Adán en el paraíso es la metáfora de la situación prístina, original del hombre: la vida desnuda $y$ virgen de interpretaciones, sabiendo que tenemos que hacer nuestra vida libremente, pero sin saber cómo hacerlo. Si fuéramos autómatas esta situación no sería problemática. Nuestra conducta ya estaría prefijada y sólo seriamos espectadores de nosotros mismos. Pero la libertad es nuestro privilegio, nuestra responsabilidad, la de inventar -en su sentido etimológico, hallar- el programa íntegro de nuestra vida. Ése es el problema en que la vida humana consiste: percatarse de sí mismo en una circunstancia, sin saber nada de la circunstancia ni de mi conducta en ella. Esta distancia entre percatarse y saberse es la misma que hay entre el hombre y Dios.

"Adán en el paraíso" es un texto complejo que merecería un estudio detenido, pero ahora conviene retener sólo algunas de sus ideas. Las aquí enunciadas siguen su desarrollo, por ejemplo, con lo que Ortega más tarde llamó 'primer atributo de la vida'. ${ }^{14}$ La vida tiene conciencia de sí misma, se percata de sí, se es presente. También se sabe, pero este saber no es en principio evidente; no lo es en acto, sino en potencia. Hacemos nuestra vida interpretándola según ciertas creencias con las cuales contamos, pero en las cuales no reparamos. Todos tenemos una interpretación de todo cuanto hay, es decir, del mundo y de nosotros mismos, pero el hombre corriente - que no filosofa- no lo sabe, no repara en ello. Desde que nacemos, el trato con los demás, la escuela y el propio idioma -sedimento de teorías vetustísimas- configuran el suelo más o menos implícito de las convicciones de nuestra vida. El filósofo sólo se diferencia porque tematiza radicalmente esas convicciones, las pone en cuestión, revalidándolas o cambiándolas por otras nuevas: es toda una crítica de la vida ordinaria en la cual sale a relucir el mundo que el hombre construye sobre la circunstancia desnuda. Incorporada a la filosofía, la razón histórica de Ortega tiene por misión mostrarnos los distintos mundos en los cuales han vivido los hombres hasta el día de hoy.

\footnotetext{
2 Cf. Ortega y Gasset, J., "Adán en EL Paraíso", en O.C. II, p. 64.

13 Ídem.

${ }^{14}$ Cf. Ortega y Gasset, J., ¿Qué es filosofía?, en op. cit., p. 353-365; Principios de metafísica según la razón vital Lecciones del curso 1932-33, en op. cit., p. 565-585.
} 


\title{
3. Razón histórica del pensamiento
}

\begin{abstract}
"El pensamiento es un mecanismo mental y nada más, si bien un mecanismo que más o menos está relativamente a nuestra disposición como la Gillete con que nos hacemos la barba o el elevador con que subimos a nuestra casa." ${ }^{15}$
\end{abstract}

Siguiendo a Ortega, el mecanismo mental en funcionamiento sólo es una 'actividad'. Para que sea efectivo 'hacer' es preciso que la voluntad ponga en marcha ese mecanismo por algo y para algo, es decir, con un motivo y un fin, o dicho de otro modo, con un porqué y un para qué. ${ }^{16}$ Todo cuanto hacemos sólo se vuelve inteligible cuando aclaramos la situación en la que nos encontramos en función de esas dos coordenadas. Ahora bien: el hombre, cada vez que ejecuta una actividad, transforma su situación; va avanzando indefinidamente construyendo nuevas situaciones a partir del material de las viejas. De ahí el carácter originariamente técnico de la vida humana, que se inventa a sí misma mediante proyectos que escorzan incesantemente la circunstancia en dirección hacia el futuro. ¿¿En qué situación debió de encontrarse el hombre para tener que movilizar su intelecto con la pretensión de conocer los que las cosas son? ¿Por qué y para qué, desde Grecia, ha habido hombres que dedicaron su vida a pensar el ser de las cosas?

No basta con definir el conocimiento diciendo que consiste en pensar o en saber el ser de las 'cosas', como si el hombre siempre hubiera realizado esta actividad con toda naturalidad. El hombre no ha creído siempre que su mente sirva para conocer, por tanto, tampoco ha creído siempre que las cosas tengan un ser. Sin embargo, en el siglo pasado, Martin Heidegger quiso reavivar el problema del ser enfocando sobre él toda su filosofía. Según el filósofo alemán, el ser es obvio, evidente, comprensible de suyo. Constantemente empleamos la palabra 'ser' cuando hablamos y escribimos, y al hacerlo nos entendemos los unos a los otros. ${ }^{17}$ Heidegger llama a esto 'comprensión preontológica del ser'. Se trata de una comprensión implícita, previa a la que tendríamos si fuéramos filósofos que se hacen la pregunta ontológica, es decir, la pregunta por el ser. El carácter histórico de esta pregunta radica, según Heidegger, en su planteamiento u olvido, y en caso de plantearse, de qué modo, y en caso de responder, de qué manera. Las interpretaciones de esta tradición ontológica tienden a solidificarse y volverse obvias. Aquí es donde entra en acción la

\footnotetext{
15 Ortega y Gasset, J., Principios de metafisica según la razón vital. Lecciones del curso 1933-34, en op. cit., p. 659.

${ }^{16}$ Cf. Ibid., p. 53; La razón histórica [Curso de 1944], en op. cit., p. 659; Apuntes sobre el pensamiento: su teúrgia y su demiurgia, en op. cit., p. 11 (n.1).

${ }^{17}$ Cf. Heidegger, M., \$1, Sein und Zeit, Tübingen, Max Niemeyer Verlag, 2001, p. 4; Ser y Tiempo, Gaos, J. (trad.), Fondo de Cultura Económica, México, 1974, p. 13.
} 
destrucción, ablandando la tradición endurecida. ${ }^{18}$ Dicho en términos orteguianos, las ideas de la ontología se convierten en creencias que el hombre no pone en cuestión porque no las considera interpretaciones, sino que las toma por la auténtica realidad. Las ideas las tenemos, en cambio, las creencias nos tienen a nosotros, son el suelo que nos sostiene. Esta solidificación de las ideas de la ontología en forma de creencias es reversible, y ésa es la tarea de la destrucción heideggeriana. Sin embargo, a la luz de la filosofía de Ortega, salta a la vista que la historicidad heideggeriana (Geschichtlichkeit) no afecta radicalmente a la pregunta por el ser. Para Heidegger, el existir o Dasein se caracteriza permanentemente por la comprensión preontológica del ser. La ontología sería la radicalización conceptual de esa comprensión, que según Heidegger constituye lo humano en el hombre. ${ }^{19}$ En cambio, para Ortega, el ser es una creencia entre otras, de modo que no todos los hombres han tenido esa precompresión, por no hablar de los hombres que han filosofado, que siempre han sido cuatro gatos. Y si el ser es una creencia, también lo es su correlato: el conocimiento, que primariamente es el filosófico. Así nos lo dijo Ortega:

"Dije, frente a Heidegger, que la filosofía no nace de la extrañeza que el mundo nos produce cuando falla como sistema de enseres o utensilios, falla que nos descubriría esa su independencia de nosotros que llamamos su Ser. E indiqué que esto me parecía un error, porque no ha habido ni puede haber un momento en que el hombre no esté extrańado del mundo, y sin embargo, no siempre - menos aún, casi nunca- ha pensado que las cosas tuviesen un Ser, o lo que es igual: casi nunca se ha ocupado en filosofar. Dije, en cambio, que la filosofía nace y renace cuando el hombre pierde su fe o sistema de creencias tradicionales, y, por tanto, cae en la duda al tiempo que se cree en posesión de una nueva vía o método para salir de esta. En la fe se está, en la duda se cae y en la filosofía se sale de ésta al Universo". ${ }^{20}$

En este párrafo de La idea de principio en Leibniz Ortega presenta, en síntesis, el problema del conocimiento filosófico desde la razón histórica. Empecemos donde Ortega empieza: con Heidegger. ${ }^{21}$ Como es sabido, dentro del proyecto general de Heidegger de tratar el problema del sentido del ser, el filósofo alemán despliega una ontología de un ente especial, el Dasein o existir humano, el cual está en el mundo, en un trato (Umgang) con los demás entes, ocupándose (Besorgen) siempre de algún utensilio (Zeug) que está inmerso en una totalidad de enseres (Zeugganzes), en referencia (Verweisung) los unos con los otros y todos conmigo 'en

\footnotetext{
${ }^{18}$ Cf. Heidegger, M., \$6, Sein und Zeit, op. cit., pp. 19-27; Ser y Tiempo, op. cit., pp. 30-37.

19 "Die Seinsfrage ist dann aber nichts anderes als die Radikalisierung einer zum Dasein selbst gehörigen wesenhaften Seinstendenz, des vorontologischen Seins-verständnisses” (cf. \$4, Sein und Zeit, op. cit., p.15; Ser y Tiempo, op. cit., p. 24).

20 Ortega y Gasset, J., La idea de principio en Leibniz, en op. cit., p. 1130.

${ }^{21}$ Cf. Heidegger, M., 15-18\$, Sein und Zeit, op. cit., pp. 66-88; Ser y Tiempo, op. cit., pp. 80-103.
} 
vista de' (Worum-willen) mi posibilidad de ser en cuanto Dasein. Heidegger llama 'respectividad total' (Bewandtnisganzheit) al conjunto de referencias utilitarias en vista de las posibilidades que pongo en juego. Esta respectividad es lo que confiere significatividad (Bedeutsamkeit) a nuestra vida aquí y ahora.

Ortega llama 'sistema de utensilios o enseres' a esa totalidad de útiles en respectividad de la que habla Heidegger. Ese sistema falla, por ejemplo, cuando un útil resulta inútil, inadecuado, quizá estropeado; quizá un martillo es demasiado pesado para mí. Entonces ocurre que el instrumento deja de 'estar a la mano' (Zuhanden) y anuncia que 'está ahí delante', 'a los ojos', 'subsistiendo' (Vorhanden). Y esto que se anuncia se radicaliza en la enunciación teórica, en la cual pensamos del martillo lo que éste es en cuanto tal, es decir, con independencia de mí. El martillo, que es un objeto artificial, de tal color y hecho de tal material, es demasiado pesado para mí. Pero quizá no lo es para un conocido mío, dispuesto a hacerme un favor. Este conocido ingresa en el antes fallido sistema de referencias de mi vida revalidándolo y entonces podemos volver a contar con el martillo.

Si en vez de un martillo se tratara de alguna realidad para nosotros enteramente desconocida, intentaríamos descubrir qué es lo que tenemos delante, qué es eso que hay ahí con independencia de mí. Recorreríamos el objeto con la percepción, lo someteríamos a ciertos experimentos para ver cómo reacciona, lo compararíamos con otras realidades y finalmente lo conceptuaríamos y enjuiciaríamos de determinada manera; todo ello para saber qué es, en su esencia, lo que tenemos delante. Pero si nos esforzamos en descubrir de modo racional el ser de los fenómenos es porque previamente creemos que las cosas tienen un ser que podemos captar cognoscitivamente. Esta creencia permea nuestra circunstancia convirtiéndola en un mundo plagado de entes, pues 'ente' significa 'lo que es', 'lo que tiene ser'. Pero no siempre ha sido así.

Ortega puso el ejemplo de las batatas. ${ }^{22}$ Para un occidental, eso que hay, a lo cual llamamos batata, tiene un ser que comparten todas las batatas del mundo. Da igual que yo sepa o no cómo es una batata, que la cultive o no, que la coma o no; lo que la batata es, lo es con independencia del hombre, y no sólo del hombre, sino de las demás cosas. Claro que la batata se relaciona con su contorno, asimila los nutrientes del suelo y aprovecha la luz del sol, pero estas relaciones con el medio son actividades que brotan de la naturaleza interna de la batata. Esta naturaleza ( $\varphi v ́ \sigma ı)$ ) es el ser de la batata, gracias al cual es autárquica, es decir, tiene el principio (’́ $p \chi \eta ́)$ del cambio en sí, un cambio por el cual la batata se orienta, no hacia otra cosa, sino

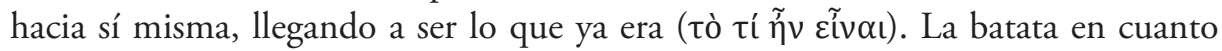

22 Cf. Ortega y Gasset, J., Comentario al Banquete de Platón, en IX, pp. 754-755. 
ente se sostiene a sí misma en el ser. Esta interpretación de la batata, que es la que tenemos cualquiera de nosotros en forma de creencia, tiene su origen en la idea de

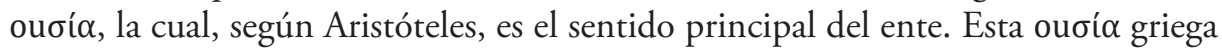
vertió su significado en el vocablo latino 'res' y ésta, a su vez, en nuestra manida palabra 'cosa'. De este modo, resulta que la palabra 'cosa', dicha tanto por el pescadero como por el catedrático, inyecta en esos hombres una vieja interpretación de cuanto hay. Las palabras nos entregan la herencia que portan del pasado: esta herencia es un mundo. Por eso decía Ortega lo siguiente:

\begin{abstract}
"Yo sostengo que el hombre no ha filosofado siempre pero, en cambio, pienso que desde que hay filosofía todos los hombres pertenecientes a la civilización occidental, o por ésta influidos, filosofan al hablar, quieran o no, en una u otra cuantía. Ejemplo de ello es que emplean el vocablo 'cosas' = 'sustancias' o sus homólogos en cada idioma. Todos, en efecto, llevamos -o arrastramos - una herencia ontológica [...] El eficaz automatismo de nuestra inveterada creencia ontológica obligándonos a tomar las cosas = sustancias no como meras ideas o hipótesis, sino como la realidad misma, nos dificulta admitir que, para otros hombres, la realidad sea muy distinta y no crean que hay verdaderamente cosas". ${ }^{23}$
\end{abstract}

¿Cómo? ¿Hay hombres que no creen que lo que hay son entes, sustancias; que no creen que las realidades sean? ¿En qué van a creer los hombres si no? Si yo conozco la naturaleza de la batata, puedo sembrarla en cualquier terreno, siempre que ese terreno tenga una naturaleza compatible con la de la planta. Aristóteles diría que la batata tiene potencias activas respecto del suelo, el cual tiene, respecto de la batata, sus potencias pasivas. Pero el mundo del hombre primitivo es muy distinto. Si fuera de la tribu de los dobu, en Papúa Nueva Guinea, creería que mis batatas no crecerán si las cultivo en el huerto de otra familia, porque las batatas de los dobu no tienen ser, no son entes, sino que consisten en una realidad mágica llamada susu. El susu, literalmente, es la leche materna, y, en sentido derivado, es el principio que explica las batatas. ${ }^{24}$

La sociedad dobu es matrilineal, así que sus familias la forman las madres y sus descendientes, y de entre éstos, los descendientes de las mujeres, y así sucesivamente. Cuando los dobu se casan heredan por parte materna las semillas de reserva para cultivar al año siguiente sus propios huertos. Pero a un hombre dobu no se le ocurriría cultivar batatas con las semillas de su padre, o con las de un amigo, ni tampoco cultivaría las semillas que hereda de su madre en el huerto de su esposa; no porque esté mal visto, simplemente creen que sería inútil. Las batatas no crecerían.

\footnotetext{
23 Ibid., pp. 753-754.

${ }^{24}$ He tenido en cuenta las obras que el propio Ortega consultó sobre los dobu, debidamente referidas al final en la bibliografía: Sorcerers of Dobu y Patterns of culture.
} 
Los dobu están convencidos de que sólo crecen las batatas cultivadas en sus propias tierras y con semillas de su línea materna.

El susu es un principio explicativo que abarca conjuntamente la familia, las tierras de cultivo y las batatas de generación en generación. ${ }^{25}$ Este susu no es el ser de la batata, y no lo es por dos razones, la primera, porque el ser esencial de la batata abarca todas las batatas, mientras que el susu de las batatas es distinto en función de las familias que las cultiven. Y esto nos lleva a la segunda razón: el ser es independiente del hombre, mientras que el susu depende de él; en rigor, depende de las mujeres. Por eso las batatas-dobu no son entes ni sustancias. Las batatas-dobu, junto con la familia y la tierra, forman 'un convoluto de realidad' que responde a un 'modo de pensar', que Ortega llama 'primigenio' o 'mágico'. Es un pensar 'confuso', pues forma 'convolutos' con realidades que simplemente tienen algo que ver. ${ }^{26}$ Confundir las cosas es ya una manera de pensarlas. ${ }^{27}$

Si por 'ser' entendemos, en sentido estricto, la creencia que heredamos de los griegos, entonces los dobu no tienen, respecto de las batatas, la precomprensión del ser que Heidegger atribuye al hombre. Y si ampliamos la palabra 'ser' para designar con ella lo que nos plazca, por ejemplo, el susu, entonces la filosofía deja de ser un afán de claridad y nos perdemos en la noche de los gatos pardos. ${ }^{28}$ Lo que es más: si el ser es una creencia, el pueblo que no crea en el ser tampoco creerá que las facultades mentales sirvan para conocer. En vez de conocimiento, habrá otro modo de pensar, otro método para saber a qué atenerse que quizá recurra a otras facultades distintas. ${ }^{29}$ El pensar confuso de los dobu es uno de los muchos modos de pensar de los que el hombre se sirve para construir un mundo sobre la circunstancia en la que nos toca vivir. Por tanto, el pensamiento es un género en el que caben diversas especies, que no son posibilidades permanentes sino invenciones históricas. ${ }^{30}$ Además

25 Cf. Ortega y Gasset, J., Comentario al Banquete de Platón, en op. cit., p. 755.

26 Cf. Ortega y Gasset, J., Idea del Teatro, en op. cit., p. 870.

27 Ídem.

${ }^{28}$ Cf. Ortega y Gasset, J., La idea de principio en Leibniz, en op. cit., p. 1121.

${ }^{29}$ No olvidemos que las fantasías de los sueños y las alucinaciones, ficciones para nosotros, han sido para los pueblos primitivos el instrumento de la verdad; cf. Ortega y Gasset, J., La razón histórica [Curso de 1944], en op. cit., pp. 644-646. En cuanto a los autores que Ortega leyó y que ilustran los modos del pensamiento primitivo, por ejemplo: cf. Lévy-Bruhl, La mentalidad primitiva, Weinberg, G. (trad. y prólogo), La Pléyade, Buenos Aires, 1972. Sobre el pensar mágico de los primitivos en Lévy-Bruhl, pero tratado filosóficamente desde la razón vital, cf. Marías, J., Introducción a la filosofía, Revista de Occidente, décima edición, Madrid, 1969, pp. 337-347.

${ }^{30}$ No es cierto que la historicidad de los modos de pensar sea una idea exclusiva de las teorías maduras de Ortega, fruto de sus lecturas antropológicas, entre ellas, por ejemplo, las de Lévy-Bruhl. Si bien es en su madurez cuando aparecen estos temas en toda su plenitud, sus gérmenes están en su juventud. Ya en 1912 Ortega hablaba de 'maneras de pensar', distinguiendo la mitología de la fisiología presocrática. En último término, esta historicidad del pensamiento llega a hundir sus raíces en la obra de su maestro neokantiano Hermann Cohen [Cf. Ortega y Gasset, J., "Notas sobre el ápeiron de Anaximandro", en O.C. VII, Madrid, Taurus y Fundación J. Ortega y Gasset, 2007, pp. 146-154; “La 'idea’ de Platón”, en op. cit., pp. 224-225]. 
de este pensar primigenio o mágico, que acabamos de describir, Ortega habla del pensar visionario o místico, el pensar mitológico o emotivo-imaginativo y el pensar perceptivo-conceptual. ${ }^{31}$ Sólo a éste último lo llamamos 'conocimiento'.

Pero no olvidemos el texto central que citamos y que estamos comentando, el de La idea de principio en Leibniz. En él Ortega achaca a Heidegger haber inflado indebidamente los conceptos de 'ente' y 'ser', desorbitado con ello el pensar filosófico que nació en Grecia. Según Ortega, la filosofía brotó cuando el hombre perdió su fe o sistema de creencias tradicionales, el cual, cayendo en la duda, supo hallar una nueva vía para salir de ésta: un nuevo pensar. Se trata del famoso paso del mithos al lógos. Antes Grecia vivía instalada en una religión primigenia, semejante a las creencias de los llamados pueblos primitivos; de ahí pasó a una concepción mítica, homérica, del mundo. La quiebra de esa fe fue una misma cosa con la construcción de la visión filosófica y científica del universo. ${ }^{32}$ Veamos ahora en qué consiste el pensamiento mítico de cuya quiebra emergió la filosofía.

En El hombre y la Gente Ortega escribió que de la circunstancia sólo tenemos, por lo pronto, impresiones. ${ }^{33}$ Merced a ellas, las sensaciones de los once sentidos, nos encontramos viviendo entre las 'cosas', tomando esta palabra no en su sentido ontológico, sino en la significación absolutamente amplia equivalente a 'algo'. Pero necesitamos saber a qué atenernos respecto de esos algos, y por eso sobre la sensación trabaja luego la interpretación. Sobre la materialidad - como ya decía en "Adán en el Paraíso" y en las Meditaciones- trabaja la forma, el sentido. ${ }^{34}$ Dos hombres escuchan el mismo sonido del agua que corre sin prisa y se acercan para mojar sus manos en la frialdad del agua oscura que espuma blancura en los desniveles de su curso. Uno es mitólogo, el otro es ontólogo. ¿Cómo interpretan esos dos hombres las sensaciones que les presenta ese algo que llamamos 'río'? Así nos lo explica Ortega:

"Podemos interpretar la 'cosa ahî que es este río de sesgo curso, como un dios. Con ello referimos el río a un imaginario mundo de dioses, o mundo divino, y lo que hemos hecho es divinizarlo. Hablamos (lógos, légein) de las cosas en tanto que dioses: teo-logizamos o mito-logizamos. Es una interpretación. Podemos igualmente referir las cosas a un mundo constituido por elementos imaginarios, cada uno de los cuales tiene estos caracteres: es idéntico a sí mis-

31 Cf. Ortega y Gasset, J., La razón histórica [Curso de 1944], en op. cit., p. 638, Comentario al Banquete de Platón, en op. cit., p. 755; La idea de principio en Leibniz, en op. cit., pp. 1132, 1151(n.2) [en la última página indicada parece que hay una errata que identifica el pensar mitológico con el visionario].

32 En cuanto a la religiosidad primitiva de Grecia, véase Psiqué, de Erwin Rohde, debidamente referida en la bibliografía utilizada. Según Ortega, se trata de un libro portentoso que cada día cobraba nueva y mayor refulgencia [cf. Idea del teatro, en op. cit., p. 859 (n.29)].

33 Cf. Ortega y Gasset, J., El hombre y la gente [Curso de 1949-1950], en op. cit., 179-180.

34 Cf. Ortega y Gasset, J., “Adán en EL Paraíso", en op. cit., p. 68; Meditaciones del Quijote, en op. cit., pp. 781,813 . 
mo, no se contradice con los demás y entra en relaciones diversas con ellos sin perder por ello su identidad. A la 'cosa ahí interpretada en tanto que elemento de ese mundo -por tanto, poseyendo esos caracteres-, decimos que es un ente, y lo que en cada una de ellas aparezca como idéntico, etcétera, lo llamamos ser de ese ente". ${ }^{35}$

Ortega contrapone aquí dos tipos de lógos: uno mítico, otro de entes. La misión de ambos es la construcción del mundo, es decir, de una figura del incanjeable universo en el cual nos toca vivir. La razón mítica y la razón que nosotros consideraríamos propiamente tal son ambas razón por igual, son razón vital, es decir, son vida que se está haciendo en constante interpretación de su circunstancia y, en general, de sí misma. Ahora bien, frente al pensar lógico, la 'mitopeia' es un pensamiento emotivo-imaginativo del mundo. Emocionado ante la regularidad de la naturaleza, el hombre inventaba narraciones que circulaban de generación en generación, adquiriendo el carácter de inmemoriales y suplantando así el pensamiento estrictamente individual de cada cual. ${ }^{36}$ No es el hombre el que piensa el mito, es la colectividad la que lo piensa por él.

La filosofía nació cuando los griegos sintieron la debilidad de sus creencias tradicionales, cuando les empezó a parecer que no hay un mundo de dioses. Entonces, redescubriendo la original extrañeza del hombre frente a su circunstancia, desorientados, necesitaron descubrir otro mundo, firme y seguro, en el que hacer pie. Ésta es la justificación del filosofar: no el fallo del sistema de útiles, sino el fallo -no parcial, sino radical- de las creencias desde las cuales interpreto esas realidades de las que me sirvo para hacer mi vida. Filosofo porque no sé a qué atenerme y para seguir viviendo, es decir, para poder seguir descubriendo quién soy en función de un mundo, esto es, de una interpretación de todo cuanto hay.

\section{Recapitulación}

A diferencia de las cosas, la vida humana no tiene un ser fijo al cual ajustarse. La vida nos es dada, pero no nos es dada hecha, hay que hacerla, cada cual la suya; por eso la vida es proyecto. La vida, propiamente, no es, sino que tiene que ser. Inmersos en su realización, vamos cambiando, siendo otros que los que ya éramos: vamos siendo y des-siendo. Por eso Ortega quiso ponernos delante el concepto tradicional de 'ser', para mostrar que no nos sirve para referirnos a la vida como

\footnotetext{
35 Ortega y Gasset, J., La idea de principio en Leibniz, en op. cit., p. 1018.

36 Cf. Ortega y Gasset, J., La idea de principio en Leibniz, en op. cit., p. 1151-1153; "El ocaso de las revoluciones", en O.C. III, Taurus y Fundación J. Ortega y Gasset, 2005, pp. 621-625.
} 
realidad radical. En efecto, para Ortega, el ser no es más que una interpretación, una creencia, correlativa a la creencia en el conocimiento en cuanto modo de pensar acerca de todo cuanto hay. De ahí que la teoría orteguiana de la vida humana no sea la ontología de un ente que destaca por una esencial referencia al ser, como lo es para Heidegger. ${ }^{37}$

Más allá de la cuestión del ente como figura del mundo, para que haya mundo es preciso que cada cual mire la realidad desde un punto de vista que le corresponde, organizando lo real para crear un panorama distinto, que es -según la expresión de Ortega en "Adán en el paraíso" - una ficción de totalidad. ${ }^{38}$ Desde ella, cuando la atención se centra en algo, ese algo se relaciona con lo demás dentro de una totalidad de conexiones. Merced a esta totalidad, aunque no se nos presente la materialidad entera de cuanto hay en la vida, todo en ella queda organizado según cierta forma: "la materialidad de la vida de cada cosa es inabordable; poseamos, al menos, la forma de la vida". ${ }^{39}$ Ya dije que Ortega repite esto mismo en las Meditaciones del Quijote, donde contrapone materialidad y sentido. Por un lado, las impresiones nos dan la carne de las cosas, su materialidad; por otro lado, las ideas -es decir, los aspectos de lo real resultantes de nuestra perspectiva- tienden relaciones que construyen estructuras de impresiones, sometiéndolas así a ordenación y generando sentido.

La filosofía significa para Ortega el mayor afán de conexión entre las cosas, responsable de que se enlacen las unas con las otras construyendo la totalidad de sentido que es el mundo. Por eso, para Ortega, la filosofía es la ciencia radical, autónoma y pantónoma, o última e integral. Esta filosofía es una metafísica, y la metafísica es construcción del mundo. La que Ortega propuso consistió en un enérgico ensayo de organizar el universo desde el punto de vista de la vida; una cultura, por tanto, desde la vida y para la vida desorientada de los espańoles, a cuyo servicio estuvo la vocación de claridad del pensador madrileño.

A la altura de nuestro tiempo no hay otro modo más auténtico ni más responsable de hacerse cargo del problema de la vida que no sea la filosofía. ${ }^{40}$ Los mundos griegos primitivo y mitológico están demasiado atrás, conservados y superados, es decir, absorbidos (Aufhebung) en el nuestro, un mundo más viejo y más complejo merced a esa dialéctica de experiencias históricas con la que, según Ortega, soñaba Dilthey. ${ }^{41}$ Pero la filosofía que nos compete acaso no se parezca a ninguna de las

\footnotetext{
37 Para una comparación entre el pensamiento de Ortega y el de Heidegger que complete el problema aquí tratado de la razón histórica del conocimiento: cf. De Nigris, F., "La razón vital de Ortega y Gasset y la analítica existencial de Heidegger", en Ideas y Valores no 148, abril 2012, pp. 115-129.

38 Cf. Ortega y Gasset, J., “Adán en EL Paraíso”, en op. cit., pp. 66, 68.

39 Ídem.

40 Cf. Ortega y Gasset, J., La idea de principio en Leibniz, en op. cit., IX, 1155.

${ }^{41}$ Cf. Ortega y Gasset, J., Historia como sistema, en op. cit., p.72
} 
anteriores, porque desnaturaliza los problemas del conocimiento y del ser gracias al método de la razón histórica, única razón que nos permite entender qué ha hecho el hombre de sí mismo mundificando la circunstancia en la que vive. El hombre no se adecúa a formas naturales, porque no es un ente. El hombre no tiene naturaleza, tiene historia:

"[La razón histórica] no cree aclarar los fenómenos humanos reduciéndolos a un repertorio de instintos y facultades [...] sino que muestra lo que el hombre hace con esos instintos y facultades, e incluso nos declara cómo han venido a ser esos 'hechos' -los instintos y las facultades-, que no son, claro está, más que ideas -interpretaciones- que el hombre ha fabricado en una cierta coyuntura de su vivir". ${ }^{42}$

42 Ibid., 80-81. 


\section{Referencias Bibliográficas}

Aristóteles, Metafísica, Calvo, T (introducción y traducción), Gredos, Madrid, 2013.

Benedict, R., Patterns of culture, Mariner books / Houghton Mifflin company, Boston / New York, 2005.

De Nigris, F., "La razón vital de Ortega y Gasset y la analítica existencial de Heidegger", en Ideas y Valores no 148, abril 2012, pp. 115-129.

Fortune, R.F., Sorcerers of Dobu, Routledge and Kegan Paul, revised edition, London, 1963.

Heidegger, M., Sein und Zeit, Tübingen, Max Niemeyer Verlag, 2001.

- Ser y Tiempo, Gaos, J. (trad.), Fondo de Cultura Económica, México, 1974.

LÉVY-BruHL, La mentalidad primitiva, Gregorio Weinberg (trad. y prólogo), La Pléyade, Buenos Aires, 1972.

Marías, J., Historia de la filosofía, Alianza Editorial, Madrid, 2008.

- Introducción a la filosofía, Revista de Occidente, décima edición, Madrid, 1969.

Ortega y Gasset, J., Obras Completas, 10 tomos, Taurus y Fundación Ortega y Gasset, Madrid, 2004-2010.

Rohde, E., Psiqué, Wenceslao Roces (trad.), Fondo de Cultura Económica, México, 1948.

DOI: http://dx.doi.org/10.15366/bp2018.18.016

Bajo Palabra. II Época. No18. Pgs: 321-336 